\title{
THREE-DIMENSIONAL MARGINAL BONE LOSS AROUND IMPLANTS SUPPORTING METAL CERAMIC AND METAL ACRYLIC SCREW RETAINED HYBRID PROSTHESIS FOR REHABILITATION OF ATROPHIED MANDIBLE. A CONE BEAM RADIOGRAPHIC STUDY
}

\author{
Shahinaz Sayed Mohamed Hassan* and Amr Abd El Bary Mahdy Emarah**
}

\begin{abstract}
Purpose: This clinical trial aimed to evaluate three-dimensional marginal bone loss around implants supporting metal ceramic and metal acrylic screw retained hybrid prosthesis for rehabilitation of atrophied mandible using cone beam computerized tomography (CBCT) after one year.
\end{abstract}

Materials and methods: Ten completely edentulous patients with mandibular ridge atrophy were randomly assigned into 2 groups; Group I; included 5 patients who received Metal ceramic screw retained hybrid prosthesis, Group II; included 5 patients who received Metal acrylic screw retained hybrid prosthesis. All patients then received 4 implants in the inter-foraminal area of the mandible using the flapless surgical approach. After osteointegration, implants were loaded by the prostheses with a distal cantilever not exceeding a 1.5 antro-posterior spread. Vertical and horizontal bone resorption was assessed at mesial, distal, buccal and lingual aspect of anterior and posterior implants using cone beam computed tomography (CBCT) at time of prosthesis insertion (baseline), 6 months and one year later.

Results: After 6 and 12 months, metal ceramic prosthesis showed significant higher vertical and horizontal bone resorption than metal acrylic prosthesis for anterior and posterior implants. Posterior implants showed significant higher vertical and horizontal bone resorption than anterior implants for metal ceramic group only and no difference in bone loss between anterior and posterior implants in metal acrylic group was noted. For both groups and implant positions, vertical and horizontal bone resorption at 12 months significantly increased compared to 6 months

Conclusion: Within the limitations of this study, metal acrylic cantilevered prosthesis for screw retained hybrid restoration of edentulous atrophied mandible may be recommended than metal ceramic prosthesis as it was associated with lesser vertical and horizontal bone resorption around the implants (especially the posterior ones) after one year follow up period.

* Lecturer, Department of Removable Prosthodontics, Faculty of Dentistry, Beni-Suef University, Egypt.

** Lecturer, Department of Removable Prosthodontics, Faculty of Dentistry, Fayoum University, Fayoum, Egypt 


\section{INTRODUCTION}

Atrophic mandible shows a significant challenge to successful oral rehabilitation with dental implants ${ }^{1}$. This condition usually results in construction of unsatisfactory ill fitted dentures, and consequently reduced oral function, reduce patient comfort and satisfaction and causes psychosocial problems ${ }^{2,3}$. Although bone grafting procedures contribute to increase denture-bearing area, thereby contributing to improvement of the retention and stability, it can significantly increase patient morbidity, costs, and treatment time ${ }^{4,5}$. Rehabilitation of completely edentulous atrophied mandible can be accomplished with various implant prosthesis, such as implant assisted overdentures, fixed implant supported prostheses with All on four implant concept $^{6}$, or fixed implant supported hybrid prosthesis ${ }^{7}$

Fixed-detachable hybrid implant prostheses are cantilevered restorations that are screwed to inter-foraminal implants. They are indicated in case of insufficient bone in the posterior jaw areas with reduced mucosal support ${ }^{8}$.Such prosthesis composed of a metallic framework covered with heat-polymerized resin and prosthetic teeth or pink porcelain and porcelain teeth ${ }^{8}$. The length of cantilever recommended to be 1.5-2 times of the antro-posterior spread (distance between the line connecting the two most distal implants and the centre of the implant most distant to that line ${ }^{9}$ ) to allow optimal load distribution to the implants. ${ }^{10}$ The choice between acrylic or ceramic hybrid prosthesis depend on several factors as inter-arch space, amount of lip support, and esthetic demands of the patients ${ }^{11,12}$. A metal-acrylic fixed hybrid restoration is indicated with moderate-to-severe bone loss, to restore the lip and cheek support, with its acrylic resin base $\mathrm{e}^{13}$ and to provide good esthetics, function, and speech ${ }^{14}$. Despite advantages of such prosthesis as reduction of costs and surgical complications, biological and technical complications as implant loss, marginal bone loss, peri-implant soft-tissue complications, mechanical complications (fracture, especially at the junctions between distal abutments and cantilevered segments) are frequent. ${ }^{15}$

Evaluation of peri-implant marginal bone loss as a result of increased functional load and surgical trauma, is a crucial clinical aspect for determination of implant success and survival ${ }^{16-19}$. However, most of studies evaluated bone loss using standardized periapical radiographs which has several limitations due to the two-dimensionality nature of the radiographs, thus mesial and distal proximal bone loss only can be evaluated and evaluation of the buccal and lingual bone resorption around the implant is not possible. Moreover, the majority of such investigations reported vertical bone loss (in apico-coronal dimension) only and neglected the evaluation of horizontal bone loss (in mesio distal direction) of the crater defect around the implants ${ }^{20,21}$. Cone-beam computed tomography (CBCT) provides three-dimensional images cross sectional images ${ }^{22}$ that allow visualization of the bucco-lingual bone around the implants ${ }^{23}$. Therefore, the aim of the present investigation was to evaluate three-dimensional marginal bone loss around implants supporting metal ceramic and metal acrylic screw retained hybrid prosthesis for rehabilitation of atrophied mandible using cone beam computerized tomography (CBCT). The null hypothesis was that there would be no significant difference in 3-dimensional bone loss between the 2 types of the prosthesis after one year.

\section{MATERIALS AND METHODS}

\section{Patient enrollment}

Ten completely edentulous patients ( 6 females and 4 males, mean age of 58 year) with maladaptive experience of wearing mandibular denture due to mandibular ridge atrophy were enrolled in this study from the outpatient clinic of the Prosthodontic Department. The inclusion criteria of the selected patients were: 1) Patients presented clear preference for a fixed implant-supported rehabilitation, 2) Sufficient bone quantity (class IV-V according 
to Cawood and Howell ${ }^{24}$ and quality (verified cone beam computerized tomography) in the interforaminal area of the mandible to receive standard implants of at least $11 \mathrm{~mm}$ length and $3.75 \mathrm{~mm}$ in diameter (average bone height was $15.2 \mathrm{~mm}$ ), 3) Sufficient restorative space of at least $15 \mathrm{~mm}$ to accommodate both types of tested prosthesis. And 4) Last extraction not less than one year. Exclusion criteria include: 1) General contraindications for surgical procedures such as patients with head and neck radio therapy, patients with bleeding disorders, hepatic patients, 2) Patients with metabolic disorders that affect osseointegration such as diabetes mellitus, and osteoporosis, 3) Long term immunosuppressive and corticosteroid drug therapy and 4) smoking patients (even patients who smoke one cigarette per day were excluded). After the patients were informed about the line of treatment and the need for regular and frequent recalls, they all signed a written consent. The study was conducted according to the ethical principles stated and approved by the ethical committee of the faculty of dentistry Beni-Suef University (Approval No FDBSUREC/11022020/MS). The patients were categorized by age, gender, and bone height in the mandibular anterior region and were randomly assigned into 2 groups using balanced randomization, then comparison of baseline criteria between groups was made to ensure that there is no difference in age, gender, and bone height between groups to avoid selection bias. Group I; included 5 patients who received Metal ceramic screw retained hybrid prosthesis, Group II; included 5 patients who received Metal acrylic screw retained hybrid prosthesis.

\section{Surgical and prosthetic interventions}

Prior to surgery, optimal location and angulation of the implants and the correct implant length were assessed using a radiographic stent and cone beam CT (CBCT, i- CAT Vision ${ }^{\circledR}$, Imaging Sciences International, Hatfield, PA, USA). Mandibular old denture was duplicated to be used as a radiographic template. Gutta purcha were fixed to the polished (buccal, labial and lingual) surfaces of the denture ${ }^{25}$. Each case was scanned using double scan protocol. The first scan was for the denture alone while the second scan was for the patient while wearing his/ her denture. A mucosal supported surgical guide was constructed by prototyping technology using 3D image-based software (OnDemand3DApp Software; CyberMed Inc). A surgical kit including sleeves and standardized drills (supplied by the radiologist) was used for osteotomy preparation. Each patient received 4 implants (Tiologic, Dentarum, Germany, diameter=3.7, and length $=11$ or $13 \mathrm{~mm}$ ), in the interforaminal area of the mandible using the flapless surgical approach. All surgeries were carried out with infiltration anesthesia (lidocaine with epinephrine). The osteotomy sites were prepared following the drilling sequence provided by the manufacturer's surgical universal kit. The surgical guide was fixed to the mandibular bone using fixation screws of the surgical kit (fig 1). Standardized drills supplied with the kit was used for osteotomy preparation through the sleeves of the guide. Implants were inserted with a minimum $35 \mathrm{Ncm}$ torque. Healing abutments were connected and the mandibular dentures were relined with soft liner 2 weeks after implant placement.

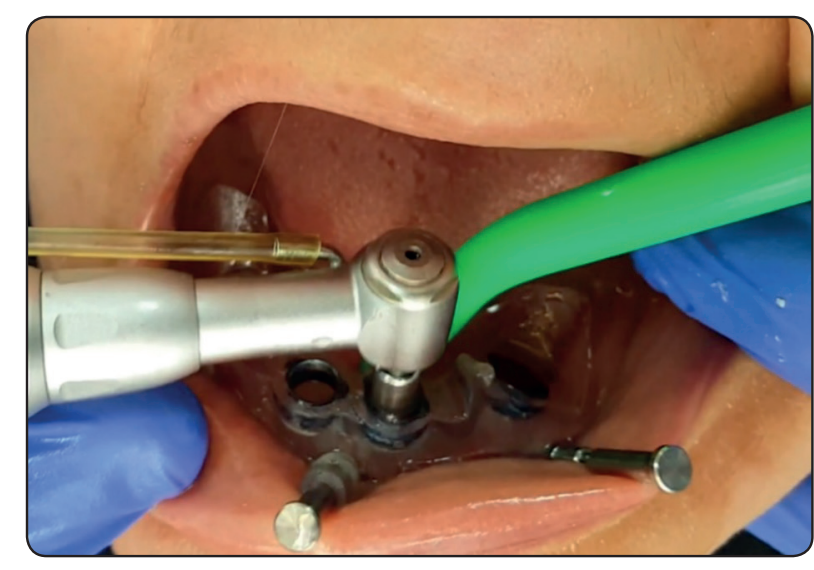

Fig. (1) Implant osteotomy preparation using the mucosal supported printed surgical guide 
Three months after implant insertion (after osseointegration), straight multiunit abutments for screw retained prosthesis were threaded to the implant fixtures (fig 2). Preliminary mandibular impressions were made using irreversible hydrocolloid impression material (CA 37, Cavex Holland BV, Haarlem, Netherlands). A special tray was constructed over the cast with openings opposing to implant areas to be used for open tray impression technique ${ }^{26}$. Long transfer impression copings were threaded to the multiunit abutments and splinted with resin pattern (Pattern Resin LS; GC America) to avoid movement of the transfer copying during the impression. The light consistency rubber base was injected around the copings and the impression was completed with heavy body material. The abutment analogues were attached to the impression post and the impression was poured to obtain the master cast. Plastic caps were screwed to the abutment analogues on the master cast.

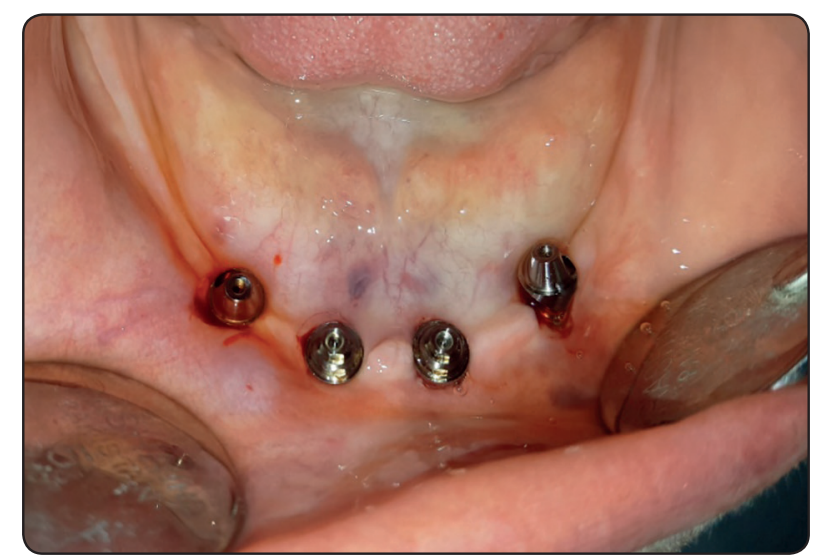

Fig. (2) Connection of multiunit abutments in patient mouth

For Group I (metal ceramic prosthesis), the cast was scanned using a CAD/CAM device (Ceramill Map400, Amann Girrbach AG. Koblach, Austria), then a cast metal-ceramic fixed prostheses that replace lost gingival tissues with pink porcelain was planned using the software of the device. The fixed Prosthesis denture was milled using polymerized resin discs (Duralay, Reliance Dental MFG Co, Worth, IL, USA) and tried in patient mouth for passive fit. The resin pattern was cast in a nonprecious cobalt-chromium alloy (Heraenium $\mathrm{Pw}$, Heraeus-Kulzer GmbH, Hanau, Germany). The cast substructure was tried intraorally for passivity using the single screw Sheffield test. The porcelain powder was mixed with the modeling liquid, applied onto the cobalt- chromium metal substructure over the opaque layer, fired, finished and glazed (fig 3).

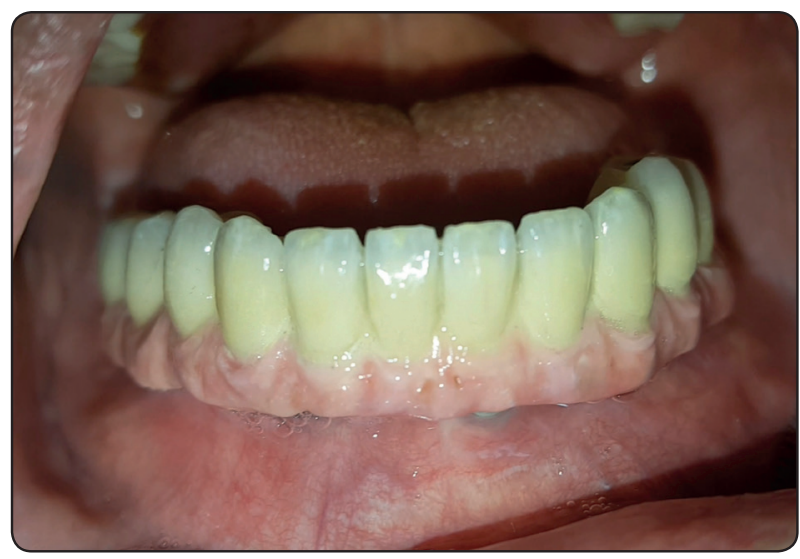

Fig. (3) Group I: Metal ceramic screw retained hybrid prosthesis

For group II (metal acrylic prosthesis), the prosthesis composed of CAD/CAM-fabricated cobalt chromium (Co-Cr) framework (bar) covered by acrylic resin teeth and pink acrylic resin that replace lost bone and gingival tissues. After scanning the cast, the metal framework was designed using the $\mathrm{CAD} / \mathrm{CAM}$ device software to give proper thickness for rigidity, and access for oral hygiene (1 $\mathrm{mm}$ space under the frame for cleaning purposes), reduced metal show, and adequate roughening of frameworks to permit good attachment of acrylic teeth and denture bases. Similarly, the framework was milled using polymerized resin discs (Duralay, Reliance Dental MFG Co, Worth, IL, USA) and tried in patient mouth for passive fit, then invested, and casted with a nonprecious cobalt-chromium alloy (Heraenium Pw, Heraeus-Kulzer GmbH, Hanau, Germany). The cast substructure was tried intraorally for passivity using the single screw Sheffield test. Artificial teeth of the same size and shade of the provisional denture were arranged over the framework and waxing up was completed. 
Intraoral try-in of cobalt-chromium framework with wax and denture teeth was made to evaluate occlusion and esthetics. After flasking, the prosthesis was processed into heat cure acrylic resin, finished and polished (fig 4).

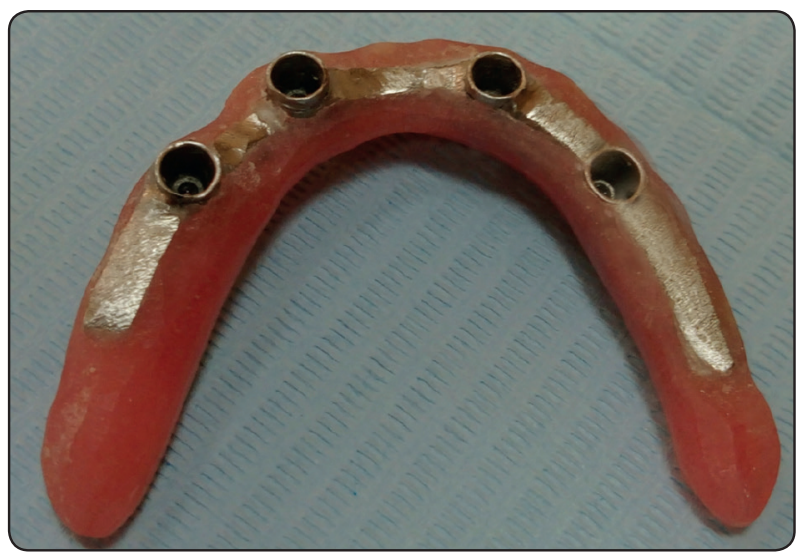

Fig. (4) Metal acrylic screw retained hybrid prosthesis

For both groups, the screw retained prosthesis has 12-unit artificial teeth in both groups ${ }^{27}$ and the cantilever length did not exceed 1.5 times the antroposterior spread. The occlusal scheme was bilateral balanced occlusion to maintain the stability of the conventional maxillary denture. The screws access holes were sealed with composite resin ${ }^{28}$. Dentures were delivered to the patients with emphasis on oral hygiene instructions and follow up visits were scheduled for data collection.

\section{Evaluation of three-dimensional marginal bone loss}

Radiographic evaluation was performed using cone beam computed tomography (CBCT) at time of prosthesis insertion (baseline,), 6 months and one year later. A CBCT was made (i-CAT®, Hatfield, PA, USA). The exposure parameters were standardized and slice thickness of $0 \mathrm{~mm}$ were used and the images were saved as DICOM-files. The implants were bisected mesiodistally and buccolingually in the axial images of the reconstructed CT. The resultant images give a panoramic view of each implant (that allow evaluation of mesial and distal bone loss) and cross-sectional images (that allow evaluation of buccal and lingual bone loss) ${ }^{22,20}$. Using the accompanied software of the CT machine (OnDemand3DApp Software, South Korea), contrast and brightness of the images were standardized and images were saved on compatible discs. Three examiners (1,2 and 3 ) with adequate training and experience in using the software performed the image analysis and measurements. On each image, vertical and horizontal alveolar bone loss was determined in the panoramic (Fig. 5) and cross-sectional images (Fig. 6). The vertical distance from implant abutment connection (A) and implant bone contact (B) was considered as the vertical bone height. The horizontal distance between most coronal point of the crater defect $(\mathrm{C})$ and the implant perpendicularly represented the horizontal bone height. Vertical and horizontal bone loss were detected by

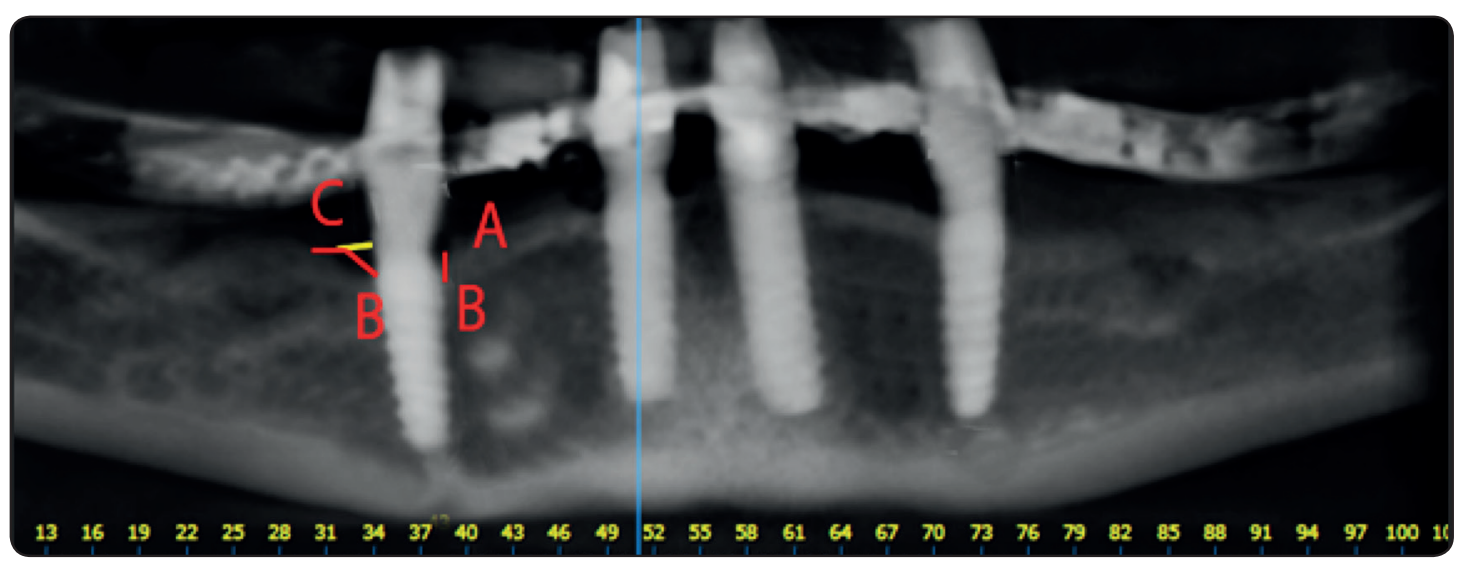

Fig. (5) The measurement of mesial and distal vertical and horizontal bone loss in the panoramic images of the CT 
subtracting bone height at 6 months and 1 years from base line ${ }^{20,29,30}$. Values of mesial, distal, buccal and lingual bone losses were averaged for each implant. There were no statistically significant differences in bone loss between the right and left implants. Therefore, calculations of bone loss of right and left implants were averaged for anterior and posterior implants and the mean was subjected to statistical analysis.

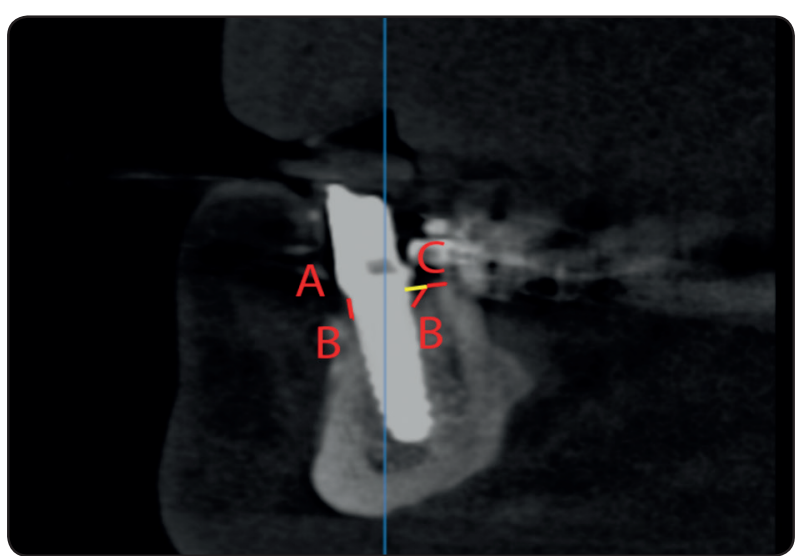

Fig. (6) The measurement of buccal and lingual vertical and horizontal bone loss in the cross-sectional images of the CT

\section{Statistical analysis}

The recorded data were normally distributed as detected by Shapiro Wilk test. Therefore, parametric tests were used. To test the inter-examiner reliability of the bone loss measurements, alpha Cronbach test was used. Independent samples t-test was used to test Vertical and horizontal bone loss between groups (metal ceramic and metal acrylic), and implant positions (anterior and posterior implants) and paired samples t-test was used to compare between 6 months and 12 months. Statistical package for social science (SPSS, Version 22, IBM, USA) was used in statistical analysis and the threshold of significance was set at $5 \%$.

\section{RESULTS}

No implant failures occurred in both groups and the survival rate was $100 \%$ in both groups. The coefficient of variation for inter-examiner reliability test was .80 which indicate that all measured values of bone resorption were reliable.

Comparisons of vertical bone resorption for anterior and posterior implants in both groups after 6 months and one year of prosthesis delivery are presented in table 1 . After 6 months, metal ceramic prosthesis showed significant higher bone resorption than metal acrylic prosthesis for anterior $(p=.002)$ and posterior $(\mathrm{p}=.007)$ implants. After 12 months, metal ceramic prosthesis showed significant higher bone resorption than metal acrylic prosthesis for anterior $(\mathrm{p}=.045)$ and posterior $(\mathrm{p}=.006)$ implants. Comparison of anterior and posterior implants is presented in the same table. Posterior implants showed significant higher bone resorption than anterior implants for metal ceramic group only after 6 months $(p=.002)$ and 12 months $(p=.001)$. On the other hand, for metal acrylic group, no difference between anterior and posterior implants was noted after 6 and 12 months.

Comparisons of horizontal bone resorption for anterior and posterior implants in both groups after 6 months and one year of prosthesis delivery are presented in table 2. After 6 months, metal ceramic prosthesis showed significant higher bone resorption than metal acrylic prosthesis for anterior $(\mathrm{p}=.047)$ and posterior $(\mathrm{p}=.006)$ implants. After 12 months, no difference in bone loss between prostheses was noted for anterior and posterior implants. Comparison of anterior and posterior implants is presented in the same table. Posterior implants showed significant higher bone resorption than anterior implants for metal ceramic group only after 6 months $(\mathrm{p}=.018)$ and 12 months $(\mathrm{p}=.047)$. On the other hand, for metal acrylic group, no difference between anterior and posterior implants was noted after 6 and 12 months.

For both groups and implant positions, vertical (fig 7) and horizontal (fig 8) bone resorption at 12 months significantly increased compared to 6 months $(\mathrm{p}<.05)$. 
TABLE (1) Vertical bone resorption (in $\mathrm{mm}$ ) for anterior and posterior implants in both groups after 6 months and one year of prosthesis delivery

\begin{tabular}{|l|c|c|c|c|}
\hline \multicolumn{5}{|c|}{6 months after prosthesis insertion } \\
\hline & & Anterior implants & Posterior implants & Independent t-test P value \\
\hline Metal ceramic & Mean \pm SD & $.34 \pm .09$ & $.54 \pm .25$ & $.002^{*}$ \\
\hline Metal acrylic & Mean \pm SD & $.28 \pm .08$ & .35 .18 & .12 \\
\hline Independent t-test & P value & $.022^{*}$ & $.007 *$ & \\
\hline & & \multicolumn{2}{|c|}{ One year after prosthesis insertion } & \\
\hline & & Anterior implants & Posterior implants & Independent t-test P value \\
\hline Metal ceramic & Mean \pm SD & $.57 \pm .09$ & $.78 \pm .26$ & $.001 *$ \\
\hline Metal acrylic & Mean \pm SD & $.51 \pm .08$ & $.58 \pm .18$ & $.006 *$ \\
\hline Independent t-test & P value & $.045^{*}$ & \\
\hline
\end{tabular}

SD; standard deviation, $* P$ is significant at $5 \%$

TABLE (2) Horizontal bone resorption (in $\mathrm{mm}$ ) for anterior and posterior implants in both groups after 6 months and one year of prosthesis delivery

\begin{tabular}{|c|c|c|c|c|c|}
\hline \multicolumn{6}{|c|}{6 months after prosthesis insertion } \\
\hline & & Anterior implants & Posterior implants & Independent t-test & (P value) \\
\hline Metal ceramic & Mean \pm SD & $.34 \pm .12$ & $.55 \pm .37$ & $.018 *$ & \\
\hline Metal acrylic & Mean \pm SD & $.26 \pm .12$ & $.27 \pm .09$ & .64 & \\
\hline \multirow[t]{3}{*}{ Independent t-test } & $P$ value & $.047 *$ & $.006^{*}$ & & \\
\hline & & \multicolumn{2}{|c|}{ One year after prosthesis insertion } & & \\
\hline & & Anterior implants & Posterior implants & Independent t-test & (P value) \\
\hline Metal ceramic & Mean \pm SD & $.41 \pm .13$ & $.59 \pm .38$ & $.047 *$ & \\
\hline Metal acrylic & Mean \pm SD & $.53 \pm .36$ & $.55 \pm .33$ & .86 & \\
\hline Independent t-test & $\mathrm{P}$ value & .15 & .75 & & \\
\hline
\end{tabular}

SD; standard deviation, * P is significant at 5\%

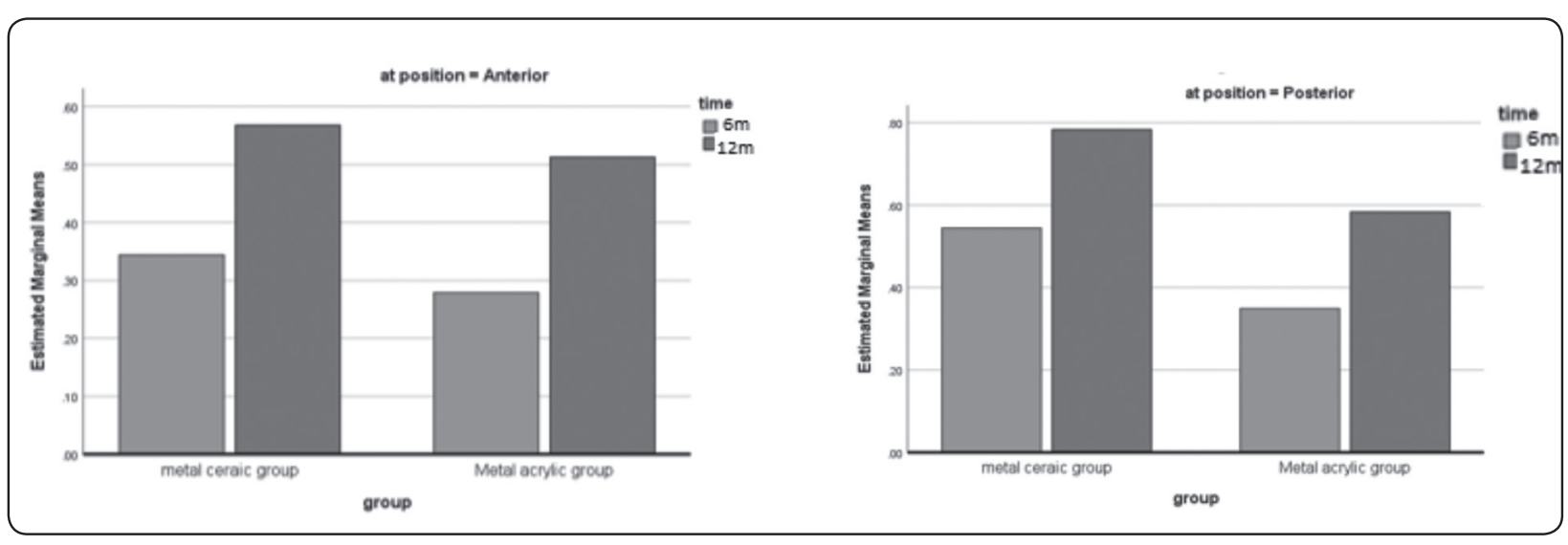

Fig. (7): Comparison of horizontal bone resorption between time intervals 


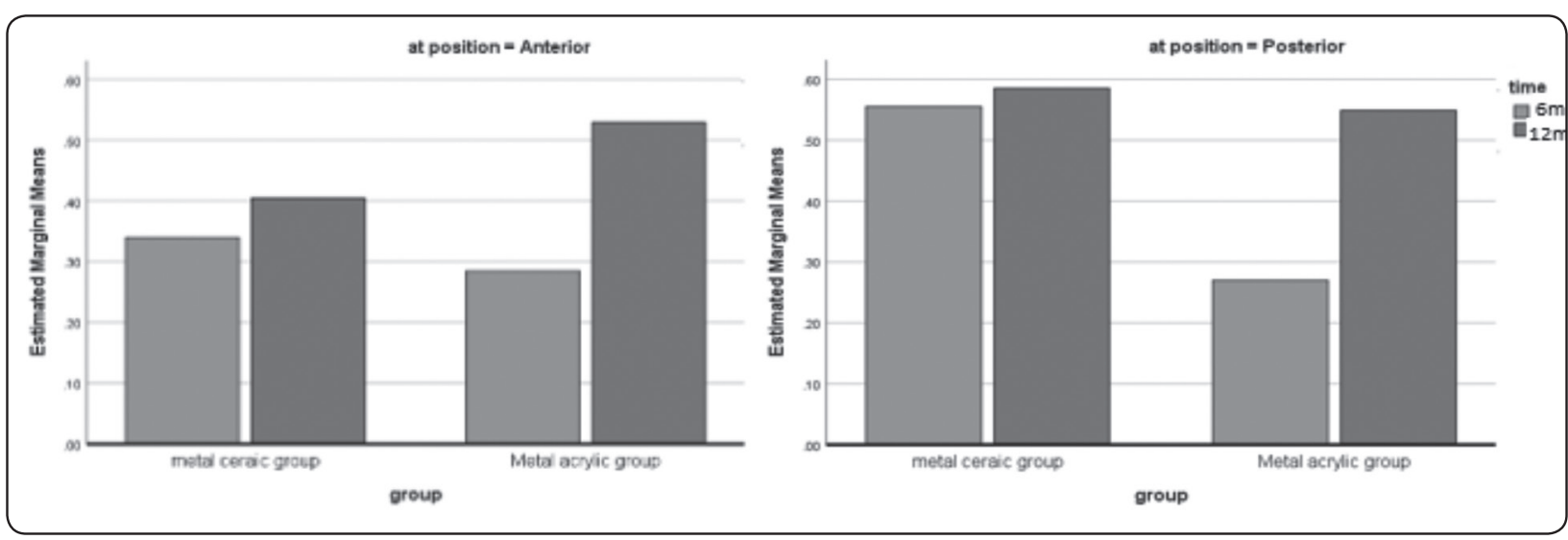

Fig. (8) Comparison of vertical bone resorption between time intervals

\section{DISCUSSION}

Cone beam computerized tomography (CBCT) was used for evaluation of marginal bone resorption as it provides information about bone loss on buccal and lingual aspects of the implants as well as mesial and distal aspects due to its three-dimensional nature. In contrast, Periapical radiograph are 2 dimensional only. Moreover, CBCT, can be used easily especially in cases with elevated floor of the mouth without causing patient discomfort as periapical radiographs do. CBCT also has no magnification or distortion as panoramic radiographs ${ }^{22,23}$. The use of CBCT in measuring bone resorption around implants was recommended by other investigators ${ }^{21,31}$. The survival rate was $100 \%$ in both groups and no implant failures occurred. This was not surprising since the interforaminal area of the mandible usually had adequate bone quality and density and are considerd one of the most successful areas for implant placement in the edentulous jaws. Also the delayed laoding protocol used in this study caused adequate bone maturation and adequate osseointegration around the implants and contributed to the high survival rate. In addition the computer guided surgery used for implant installation ensure optimal implant position in relation to anatomical structures and occlusion.

For both groups, the vertical and horizontal bone resorption values ranged from $.26 \mathrm{~mm}$ to
$.78 \mathrm{~mm}$. These values showed minimal bone loss and are located within the normal range reported in the literature $(1-1.2 \mathrm{~mm} \text { after one year })^{17}$. The reduced crestal bone resorption could be attributed to the flapless placement technique of the implants that causes minimal disruption to the periosteum, preserves peri- and endosteal blood supply, and preserves the bone height around the implants after surgery ${ }^{32-34}$. Moreover, the splinting effect of the cast substructure in both groups may have distributed the load on the implants. Furthermore, the increased bone density of the basal bone in the interforaminal area may have played a role in increasing implant stability and anchor in bone.

Vertical bone resorption has been usually evaluated in clinical studies to represent bone response to increased occlusal load. On the other hand, horizontal bone loss is used to represent bone response to peri-implant soft tissue inflammation $^{20,21}$. The metal ceramic prosthesis showed significantly higher vertical and horizontal bone resorption than metal acrylic prosthesis for anterior and posterior implants. The increased vertical bone loss with metal ceramic group may be attributed to the increased impact strength values of porcelain teeth compared to acrylic teeth which transfer more load to the implant during mastication. On the other hand the acrylic artificial teeth have a higher shock absorbability than porcelain teeth which reduce force transmission to the implants ${ }^{35}$ and could be 
responsible for reduced vertical marginal bone loss in this group. In agreement with this explanation, other authors found that acrylic hybrid prosthesis reduced the impact force and dynamic occlusal loads, in addition to be highly esthetic restorations and less expensive to fabricate ${ }^{11,12}$. The increased horizontal bone loss with metal porcelain group may be due to difficulty of cleaning and performing adequate oral hygiene in this group. It should be noted that, in this study the acrylic resin was finished to the metal at the buccal and lingual surface of the prothesis and the tissue surface of the prosthesis was left as a polished metal with $1 \mathrm{~mm}$ space for cleaning purposes. This may have helped the patients wearing metal acrylic prostheses to adequately clean them and perform good oral hygiene compared to metal porcelain prothesis which need total removal to clean the prothesis. Although not measured in this study, the lack of cleaning may lead to increased plaque accumulation, and increased mucosal inflammation ${ }^{36,37}$ which may have been responsible for the increased horizontal bone loss in the metal porcelain group.

Posterior implants showed significantly higher bone resorption than anterior implants for metal ceramic group only and no differnece in anterior and posterior implants were noted for acrylic group. In line with this finding, Sadowsky \& Caputo $^{38}$ noted that cantilevered anchorage systems generated the highest stress to the ipsilateral distal implant when the denture is not adequately supported ${ }^{38}$. Excessive loads occur at the cantilever area when occlusal force is applied to the cantilevers ${ }^{39}$. Also Padhye et al..$^{40}$ showed that greatest amount of stress was seen around the distal-most region of the distal-most implant when implants were used to support cantilevered fixed restorations in mandible. They added that when extension of the cantilever extended beyond $15 \mathrm{~mm}$, this led to a greater stress in the lingual cortical plate, which could eventually compromise the integrity of the implants. This is especially evident when porcelain teeth are used due to increased biting forces compared to acrylic teeth and increased impact forces of porcelain teeth as stated previously. On the other hand the dampening and shock absorption effect of acrylic teeth together with their reduced masticatory and biting force could be responsible for the lack of difference in bone loss between anterior and posterior implants in this group.

Bone resorption progressed significantly with time in both groups. This may be due to bone remodeling which occurs after implant placement and bone response to healing combined with function stresses ${ }^{41}$. Over all the null hypothesis was denied as metal porcelain hybrid prosthesis was associated with significantly higher marginal bone resorption than metal acrylic prosthesis and especially the posterior implants may be at risk of increased bone loss by time. Therefore, long term randomized trials with sufficient sample size are still needed to verify-bone resorption around implants in both types of prosthesis over a longer period of time. The limitations of this study included small sample size, the short evaluation period, and lack of evaluation of peri-implant soft tissues.

\section{CONCLUSION}

Within the limitations of this study, metal acrylic cantilevered prosthesis for screw retained hybrid restoration of edentulous atrophied mandible may be recommended than metal ceramic prosthesis as it was associated with reduced vertical and horizontal bone resorption around the implants (especially the posterior ones) after one year follow up period.

\section{REFERENCES}

1. Santagata M, Guariniello L, D'Andrea A, Tartaro G. A modified crestal ridge expansion technique for immediate placement of implants: a report of three cases. J Oral Implantol. 2008;34:319-24.

2. Muller F, Hernandez M, Grutter L, Aracil-Kessler L, Weingart D, Schimmel M. Masseter muscle thickness, chewing efficiency and bite force in edentulous patients with fixed and removable implant-supported prostheses: a cross-sectional multicenter study. Clin Oral Implants Res. 2012;23:144-50. 
3. Awad MA, Lund JP, Shapiro SH, Locker D, Klemetti E, Chehade A et al. Oral health status and treatment satisfaction with mandibular implant overdentures and conventional dentures: a randomized clinical trial in a senior population. Int J Prosthodont. 2003;16:390-6.

4. Stellingsma C, Vissink A, Meijer HJ, Kuiper C, Raghoebar GM. Implantology and the severely resorbed edentulous mandible. Crit Rev Oral Biol Med. 2004;15:240-8.

5. Stellingsma K, Raghoebar GM, Meijer HJ, Stegenga B. The extremely resorbed mandible: a comparative prospective study of 2-year results with 3 treatment strategies. Int J Oral Maxillofac Implants. 2004;19:563-77.

6. Malo Bo R, Nobre M. Concept with Brlaanemark System Itextregistered Implants for Completely Edentulous Mandibles : A Retrospective Clinical Study. Implant Dent. 2003:2-9

7. Sadowsky SJ. The implant-supported prosthesis for the edentulous arch: design considerations. J Prosthet Dent. 1997;78:28-33.

8. Castillo-Oyague R, Suarez-Garcia MJ, Perea C, Rio JD, Lynch CD, Gonzalo E et al. Validation of a new, specific, complete, and short OHRQoL scale (QoLFAST-10) for wearers of implant overdentures and fixed-detachable hybrid prostheses. J Dent. 2016;49:22-32.

9. English C. Critical AP spread. The Implant Society: [periodical]. 1989; 1:2-3.

10. McAlarney ME, Stavropoulos DN. Theoretical cantilever lengths versus clinical variables in fifty-five clinical cases. The Journal of prosthetic dentistry. 2000;83:332-43.

11. Thalji G, Bryington M, De Kok IJ, Cooper LF. Prosthodontic management of implant therapy. Dent Clin North Am. 2014;58:207-25.

12. Misch C. Dental Implant Prosthetics. 2nd Ed Elsevier Mosby 2015:576-7.

13. Tallarico M, Canullo L, Pisano M, Peñarrocha-Oltra D, Peñarrocha-Diago M, Meloni SM. An up to 7-Year Retrospective Analysis of Biologic and Technical Complication With the All-on-4 Concept. J Oral Implantol. 2016; 42:265-71.

14. Egilmez F, Ergun G, Cekic-Nagas I, Bozkaya S. Implantsupported hybrid prosthesis: Conventional treatment method for borderline cases. Eur J Dent. 2015;9:442-8.
15. Pjetursson BE, Thoma D, Jung R, Zwahlen M, Zembic A. A systematic review of the survival and complication rates of implant-supported fixed dental prostheses (FDPs) after a mean observation period of at least 5 years. Clin Oral Implants Res. 2012;23 Suppl 6:22-38.

16. Albrektsson T, Isidor F. Consensus report of session IV. In: Lang NP, Karring T, eds. Proceedings of the 1st European Workshop on Periodontology. London, PA: Quintessence, 1993:365-9.

17. Albrektsson T, Zarb G, Worthington P, Eriksson AR. The long-term efficacy of currently used dental implants: a review and proposed criteria of success. Int J Oral Maxillofac Implants. 1986;1:11-25.

18. Roos J, Sennerby L, Lekholm U, Jemt T, Grondahl K, Albrektsson T. A qualitative and quantitative method for evaluating implant success: a 5-year retrospective analysis of the Branemark implant. Int J Oral Maxillofac Implants. 1997;12:504-14.

19. Strietzel FP, Nowak M, Kuchler I, Friedmann A. Peri-implant alveolar bone loss with respect to bone quality after use of the osteotome technique: results of a retrospective study. Clin Oral Implants Res. 2002;13:508-13.

20. Elsyad MA, Al-Mahdy YF, Fouad MM. Marginal bone loss adjacent to conventional and immediate loaded two implants supporting a ball-retained mandibular overdenture: a 3-year randomized clinical trial. Clin Oral Implants Res. 2012;23:496-503.

21. Elsyad MA, Khirallah AS. Circumferential bone loss around splinted and nonsplinted immediately loaded implants retaining mandibular overdentures: A randomized controlled clinical trial using cone beam computed tomography. J Prosthet Dent. 2016;116 741-8

22. Raes F, Renckens L, Aps J, Cosyn J, De Bruyn H. Reliability of circumferential bone level assessment around single implants in healed ridges and extraction sockets using cone beam CT. Clin Implant Dent Relat Res. 2013;15:661-72.

23. Naitoh M, Hayashi H, Tsukamoto N, Ariji E. Labial bone assessment surrounding dental implant using cone-beam computed tomography: an in vitro study. Clin Oral Implants Res. 2012;23:970-4.

24. Cawood JI, Howell RA. A classification of the edentulous jaws. Int J Oral Maxillofac Surg. 1988;17:232-6.

25. Elsyad MA, Mahanna FF, Elshahat MA, Elshoukouki AH. Locators versus magnetic attachment effect on peri- 
implant tissue health of immediate loaded two implants retaining a mandibular overdenture: a 1-year randomised trial. J Oral Rehabil. 2016;43:297-305.

26. Elsyad MA, El-Waseef FA, Al-Mahdy YF, Fouad MM. A comparison of mandibular denture base deformation with different impression techniques for implant overdentures. Clin Oral Implants Res. 2013;24 Suppl A100:127-33.

27. Malo P, de Araujo Nobre M, Lopes A, Francischone C, Rigolizzo M. "All-on-4" immediate-function concept for completely edentulous maxillae: a clinical report on the medium (3 years) and long-term (5 years) outcomes. Clin Implant Dent Relat Res. 2012;14 Suppl 1:e139-50.

28. Sannino G, Bollero P, Barlattani A, Gherlone E. A Retrospective 2-Year Clinical Study of Immediate Prosthetic Rehabilitation of Edentulous Jaws with Four Implants and Prefabricated Bars. J Prosthodont. 2017;26:387-94.

29. Elsyad MA, Shoukouki AH. Resilient liner vs. clip attachment effect on peri-implant tissues of bar-implant-retained mandibular overdenture: a 1-year clinical and radiographical study. Clin Oral Implants Res. 2010;21:473-80.

30. Elsyad MA, Elsaih EA, Khairallah AS. Marginal bone resorption around immediate and delayed loaded implants supporting a locator-retained mandibular overdenture. A 1-year randomised controlled trial. J Oral Rehabil. 2014; 41:608-18.

31. Razavi T, Palmer RM, Davies J, Wilson R, Palmer PJ. Accuracy of measuring the cortical bone thickness adjacent to dental implants using cone beam computed tomography. Clin Oral Implants Res. 2010;21:718-25.

32. Ahn MR, An KM, Choi JH, Sohn DS. Immediate loading with mini dental implants in the fully edentulous mandible. Implant Dent. 2004;13:367-72.

33. Bulard RA, Vance JB. Multi-clinic evaluation using minidental implants for long-term denture stabilization: a preliminary biometric evaluation. Compend Contin Educ Dent. 2005;26:892-7.

34. Jeong SM, Choi BH, Li J, Kim HS, Ko CY, Jung JH et al. Flapless implant surgery: an experimental study. Oral Surg Oral Med Oral Pathol Oral Radiol Endod. 2007;104:24-8.

35. Kawano F, Ohguri T, Ichikawa T, Mizuno I, Hasegawa A. Shock absorbability and hardness of commercially available denture teeth. Int J Prosthodont. 2002;15:243-7.

36. Francetti L, Agliardi E, Testori T, Romeo D, Taschieri S, Del Fabbro M. Immediate rehabilitation of the mandible with fixed full prosthesis supported by axial and tilted implants: interim results of a single cohort prospective study. Clin Implant Dent Relat Res. 2008;10:255-63.

37. Francetti L, Romeo D, Corbella S, Taschieri S, Del Fabbro M. Bone level changes around axial and tilted implants in fullarch fixed immediate restorations. Interim results of a prospective study. Clin Implant Dent Relat Res. 2012;14:646-54.

38. Sadowsky SJ, Caputo AA. Effect of anchorage systems and extension base contact on load transfer with mandibular implant-retained overdentures. J Prosthet Dent. 2000;84:327-34.

39. McAlarney ME, Stavropoulos DN. Determination of cantilever length-anterior-posterior spread ratio assuming failure criteria to be the compromise of the prosthesis retaining screw-prosthesis joint. Int J Oral Maxillofac Implants. 1996;11:331-9.

40. Padhye OV, Herekar M, Patil V, Mulani S, Sethi M, Fernandes A. Stress Distribution in Bone and Implants in Mandibular 6-Implant-Supported Cantilevered Fixed Prosthesis: A 3D Finite Element Study. Implant Dent. 2015; 24:680-5.

41. Hohlweg-Majert B, Metzger MC, Kummer T, Schulze D. Morphometric analysis - Cone beam computed tomography to predict bone quality and quantity. J Craniomaxillofac Surg. 2011;39:330-4. 